\title{
Can Children Really Create Knowledge?
}

\section{Les enfants peuvent-ils créer du savoir?}

Carl Bereiter and Marlene Scardamalia

Authors
Carl Bereiter, Professor Emeritus, Institute for Knowledge Innovation and Technology, OISE,
University of Toronto. Correspondence regarding this article can be sent to:
carl.bereiter@utoronto.ca.
Marlene Scardamalia, Presidents' Chair in Education and Knowledge Technologies, Director,
Institute for Knowledge Innovation and Technology, OISE, University of Toronto.

\section{Abstract}

Can children genuinely create new knowledge, as opposed to merely carrying out activities that resemble those of mature scientists and innovators? The answer is yes, provided the comparison is not to works of genius but to standards that prevail in ordinary research communities. One important product of knowledge creation is concepts and tools that enable further knowledge creation. This is the kind of knowledge creation of greatest value in childhood education. Examples of it, drawn from elementary school knowledge-building classrooms, are examined to show both the attainability and the authenticity of knowledge creation to enable knowledge creation. It is mainly achieved through students' theory building, and it is a powerful way of converting declarative knowledge to productive knowledge.

\section{Résumé}

Les enfants peuvent-ils créer une nouvelle connaissance, plutôt que de mener des activités qui s'apparentent à celles des scientifiques et des inventeurs d'expérience ? La réponse est oui, à condition que la comparaison ne se fasse pas avec des travaux effectués par des génies, mais avec des normes prévalant dans la plupart des communautés de recherche. Un des produits importants de la création de la connaissance est l'élaboration de concepts et d'outils qui permettent une création de la connaissance plus poussée. Voilà le type de création de connaissance possédant la plus grande valeur dans l'éducation d'un enfant. Des exemples, tirés de classes du primaire en coélaboration de connaissances, sont examinés pour démontrer la possibilité d'atteindre de tels résultats, ainsi que l'authenticité du processus conduisant à la création du savoir. Ces objectifs sont principalement atteints grâce à une construction théorique provenant des élèves. Il s'agit là d'une manière puissante de passer d'une connaissance déclarative à une connaissance productive. 
In many publications spread over two decades, we have argued for and showed examples of knowledge building-or its synonym, knowledge creation-by elementary school students. Articles in this special issue of the Canadian Journal of Learning and Technology, provide a variety of other examples. Yet even sympathetic commentators have questioned whether what we are talking about is really knowledge creation. School students, they will say, do not produce knowledge new to the world. Although it may be new to them, it is at best an approximation to the knowledge of experts in the subject. But what does it mean to really create knowledge? In this article we try to examine more deeply what it means for students to create public knowledge. This is an important issue not only for childhood education but for education up to adulthood, for it is only at advanced graduate levels that students are normally expected to make a "contribution to knowledge." Does genuine knowledge creation have to wait that long? Does existing knowledge have to be mastered before students can venture into knowledge innovations themselves? Knowledge Building, as an educational approach, is based on the premise that genuine knowledge creation does not have to wait. A core principle of Knowledge Building (see "A Brief History of Knowledge Building," present issue) is "Real ideas, authentic problems." Real ideas are ideas that originate from the participants, not copied ideas; and authentic problems are problems whose solution makes a contribution to community knowledge, not problems whose only value is in the learning that ensues. So is "Real ideas, authentic problems" a principle that can be realistically applied to children's knowledge building efforts? The answer depends on whether children can really be expected to create new knowledge.

Before proceeding, we must make clear that we are not talking about knowledge creation in the sense conveyed by the popular slogan, "Learners construct their own knowledge." From a cognitive psychological standpoint (including but not limited to the standpoint of Piagetians) this is true of all meaningful learning. We are talking about knowledge creation as the kind of productive work knowledge creating companies do to merit that label and that goes on in research and engineering laboratories, in creative scholarship, and in innovative groups of all sorts. For the time being, at least, we want to treat knowledge creation as an either/or proposition. Thus, children are either creating knowledge or they are not; there are not varying degrees of knowledge creation, such that we might give the National Research Council a score of 95 percent and an intellectually lively Grade 5 class a score of 28 percent. Children are always learning but they are not always creating knowledge. Indeed, some children may never have experienced it, may never have engaged in the deliberate and successful effort to advance a knowledge frontier.

Rule to prevent unfair exclusions: The standard for what constitutes genuine knowledge creation by children should not be more severe than the standard for crediting a doctoral dissertation or journal article with having made a "contribution to knowledge." When we think about knowledge creation, the examples that come to mind are likely to be works of genius. But thousands of articles are published each month that do not represent work of Nobel prize caliber yet the authors' peers have recognized them as contributions to the advancement of their field. Not every cognitive accomplishment counts as knowledge creation. But if we set the 
bar so high that it excludes many people who earn their livings at least in part by knowledge creation, we will automatically-and unfairly-exclude almost all school students.

\section{Knowledge Creation is Problem Solving With a Difference}

Every time you solve a problem you create knowledge of a sort, but to be credited as knowledge creation your solution must meet additional criteria: It has to have value to people other than yourself, its value must endure for some time beyond the moment, it must have application beyond the situation that gave rise to it, and it must display some modicum of creativity (however that is judged). These requirements are not necessarily very stringent, but most of the problem solving we do in everyday life falls short on one or more of these counts. Similarly, most of the problem solving students do in regular schoolwork fails to qualify. Solving an arithmetic word problem, for instance, may on occasion involve some creative thinking, but the solution has no value beyond what the student learns from working on the problem. But more constructivist kinds of problem solving may also fail to qualify as knowledge creation. One popular elementary school activity of this sort is planning a trip to Mars. As a learning activity, planning a trip to Mars has much to recommend it. Students can acquire worthwhile knowledge of astronomy, rocketry, and biology from working on it. But the problem solution-the plan for the Mars voyage-is unlikely to be of value to other people, or to be applicable to anything else the students do. Of course, while engaged in planning a Mars voyage or any other kind of knowledge-rich or idea-rich activity, students might raise deeper problems or come up with bigger ideas that could serve as objects of knowledge building. But in the typical learning activity, whether constructivist or not, this would be an unplanned side effect (Scardamalia \& Bereiter, 2007). By contrast, in a Knowledge Building approach, producing "real ideas" to address "authentic problems" is not an occasional excursion, it is one of the cardinal principles of the approach.

\section{Knowledge Creation that Enables Further Knowledge Creation}

Knowledge creation can take many forms and serve many purposes. It can serve practical purposes and it can answer questions. One of its most important functions, however, is to enable further knowledge creation. This is what gives science and other progressive disciplines their dynamic character. Darwin's theory of evolution partly answered the question of how species originate, but the concept of natural selection has played a much larger role, not only in the progress of biology but also in other areas such as creativity and medicine (Dennett, 1995; Simonton, 1999). Although probability theory was originally developed to analyze games of chance, and is still used for that purpose, it is now an essential tool in many kinds of research, from epidemiology to climate studies. A modern society could scarcely function without it. Basic research, we may say, is basic in the sense that its products underlie further knowledge creation. The greatest knowledge creating achievements have effects that propagate throughout the culture, affecting future knowledge creation in a vast range of areas. On a smaller scale, however, knowledge creation by children can have a similar radiating effect. 
Almost by default, knowledge creation by children will have its main value in enabling further knowledge creation. There have been instances of young people producing useful inventions and making scientifically significant discoveries. In one Knowledge Building class, Grade 5/6 students discovered the phenomenon of "learned helplessness" in Madagascan hissing cockroaches! But such accomplishments are too rare to satisfy critics who doubt that children in general are capable of authentic knowledge creation. The general case must rest, not on producing knowledge new to the world, but on producing knowledge that has an enabling effect on future knowledge creation.

Let us consider a simple example discussed in Zhang, Scardamalia, Reeve, and Messina (2009). Students in a Grade 4 class, studying light, were provided with a prism and carried out observations on refraction suggested by official curriculum guidelines. Their notes in Knowledge Forum ${ }^{\circledR}$ progressed from reporting results of their experiments to trying to clarify the concept of refraction and use it to explain their experimental findings. Questions arose about rainbows and the students began to theorize. For instance,

My theory is that the sun shines through the raindrops and storms that reacts as prisms that make a rainbow.

Whether the note's author thought of this explanation independently or whether it came from an authoritative source is incidental to the fact that the idea is commonly accepted knowledge that, by itself, would not count as knowledge creation. However, some students observed that the colours of the rainbow always appeared in the same order, and this gave rise to a variety of ideas and criticisms of ideas, culminating in the following summary:

We have figured out an answer. ... Different light frequencies make different colours. Red has the longest wavelength and travels the fastest. Violet has the shortest. ... Red always gets its place first in the rainbow because it travels faster. ... Violet is always last because it travels slower than all the other colours. The colours in between come in order from the longest frequencies to the shortest...

This, too, is an idea that can be traced back to available sources. However, if we look at the most readily available online sources, we can detect important differences. Wikipedia gives a thorough explanation that is not as technical as many scientific articles in Wikipedia, but still it is likely to intimidate Grade 4 students. An article on the same topic from the University Corporation for Atmospheric Research is laden with mathematics and thus even more likely to be inaccessible to young students. On the other hand, a website expressly designed for school students offers an explanation that is easier to read but that fails to answer the question and is more likely to confuse than to inform:

Sunlight enters each and every drop of water and the colors are given out as if the drop of water was a prism. This bending and reflecting happens at the same time in all the droplets of water and that is what forms the colors of the rainbow that you see after it rains. 
The implication, thus, is that happening "at the same time" is sufficient explanation of the rainbow. It implies that every raindrop produces the complete rainbow, whereas the Wikipedia article explains that the different colours reach the eye from different droplets at different altitudes. Although the students' explanation is not entirely clear, particularly about the relation between speed and wavelength, it has the virtue of making sense from a Grade 4 point-of-view. This did not happen by simply copying or paraphrasing. It reflects a collaborative theory-building effort. The resulting theory will not strike a knowledgeable adult as original, but it rendered one aspect of the physical world more comprehensible than it had been before. That is what we expect scientific knowledge creation to do, and the students did it.

To what extent this piece of children's theorizing enables further knowledge creation can, of course, only be determined from later events. Keeping in mind that this effort did not address a major question, such as how electricity works, we can predict that in a small way it should have provided students with some working concepts (wavelength, bending, and so forth) that they can use in subsequent inquiries about light. Beyond that, it should have bolstered the children's confidence that they can make sense of things in the seemingly mysterious area of light phenomena. For 10-year-old children that ought to be enough to credit them with authentic and worthwhile knowledge creation.

\section{Productive Knowledge}

All but the most context-bound knowledge helps in the acquisition of further knowledge. However, some kinds of knowledge are more helpful than others. Mathematics is so potent in this regard that C. P. Snow in The Two Cultures (1959) tagged mathematical ignorance as the main reason the literary intellectual culture was isolated from the scientific culture. But mere ability to solve textbook and test problems does not constitute mathematical knowledge sufficient to support the acquisition of theoretical knowledge in other fields or even more advanced knowledge of mathematics.

Let us call knowledge that is of significant use in the acquisition and creation of further knowledge productive knowledge. To become productive, knowledge must be lived by the learners. It must be worked with and used in various contexts, explored and questioned, connected not only with other explicit ideas but also with intuitions and habits. Acquiring new productive knowledge makes you in some way a different person; you perceive the world a little differently, your thoughts are structured somewhat differently, your intuitions and eventually your habits of mind undergo shifts.

Productive knowledge is a useful concept for present-day education; it can replace the now obsolete concept of mastery. The notion that one could know all there is to know in a discipline has not been credible for several centuries. Knowledge has been increasing at too rapid a rate for learning to keep up with it. In practice, "mastery" has meant learning the required content of an academic course up to a certain standard (commonly, 80 percent of the points on an achievement test). But it is possible to meet such a standard without having come anywhere 
close to mastery in a broader sense and-more to the present point-without having acquired productive knowledge.

In mathematics, there is reason to conclude that for most people there is little growth in productive knowledge beyond whole-number arithmetic.' Arithmetic with rational numbers may be mastered up to a point, but proportionality as a way of apprehending measurable aspects of the real world is grasped tenuously if at all. This in turn makes algebra inaccessible except as a collection of useless procedures. "University mathematics instructors have told us the same is true of calculus for most students, even after they have passed a supposedly rigorous introductory course. In this special issue, an article titled, "Knowledge Building and mathematics: Shifting the responsibility for knowledge advancement and engagement," by Moss and Beatty provides an account in which students do "live" algebra-that is, think algebraically in various contexts - thus creating productive mathematic knowledge for themselves.

Mathematics, however, is only the most dramatic example of the failure of schooling to develop productive knowledge-dramatic because the potential is so great and the reality is so pathetic. But productive knowledge as an educational outcome is rare across the curriculum. This summary judgment is not backed up by test data, because there are no instruments for mass testing of productive knowledge-in fact, we do not know of any tests of it at all, although such tests are conceivable. But there is a vast "misconceptions" literature (a general review is provided in Wandersee, Mintzes, \& Novak, 1994; more recent research has branched out into examining misconceptions in particular domains). This research has demonstrated time and again that students are able to pass school tests but lack productive knowledge. There are also the observations of education critics, whose data source is usually college students they have taught. But in this context that source is relevant, for if college and university students are ill equipped with productive knowledge applicable to disciplinary learning this suggests conditions for the populace at large are even worse.

We want to make it clear, however, that we are not claiming schools teach only rote knowledge. Much of what is learned in schools is meaningful, sometimes impressively so. Many schools these days promote environmental studies that students find intensely meaningfulmeaningful enough to turn many of them into environmental activists or at least activist sympathizers. But do they grasp the concepts of ecology and ecosystem to the point of opening new paths toward understanding complex systems in the natural and social world? Students may acquire a lot of meaningful knowledge about biological adaptation in different animal and plant species yet fail to gain a workable grasp of natural selection beyond the level of selection on single traits (e.g., long necks for giraffes). Yet natural selection is one of the most productive concepts ever developed in science (Dennett, 1995). Other especially productive types of knowledge have been identified as "central conceptual structures" (Case, 1992; Case \& Okamoto, 1996), "epistemic forms" (Collins \& Feruguson, 1993), and "abstract schemas" (Ohlsson, 1993). Examples in addition to ones already mentioned are knowledge of causality, story structure, probability and statistics, grammatical and rhetorical concepts, the concepts of 
function and model, extrapolation and interpolation, types of energy and force, basic concepts of genetics, physiology, culture, and group dynamics. In all of these cases, however, the disciplinary knowledge is only potentially productive and only provides tools for the creation of new knowledge as students gain experience in using it for that purpose.

In limited ways, rote knowledge can sometimes be productive. For instance, rote procedures for using a computer spreadsheet may be useful in mathematics learning, but not nearly as useful as principled understanding of the software, which makes it possible to use spreadsheets in more creative ways. In general, knowledge of school subjects is potentially productive only to the extent that it is meaningful, understood in some depth. But more is required in order for meaningful knowledge to become productive of further advances in knowledge. There are different ways of "living" new knowledge so that it becomes productive. Discourse, in such forms as argument, exposition, and reflective writing, can play a large role, along with using the knowledge in a variety of constructive, playful, and problem-solving activities. But collaborative Knowledge Building can be a particularly powerful way of converting meaningful but inert knowledge into productive knowledge. Its power derives from the fact that in Knowledge Building people deliberately use knowledge to produce new knowledge-hence, use it productively.

\section{Knowledge Building as Theory Building}

Across a very wide range of problems, Knowledge Building amounts to producing and improving theories. Invention and design may involve much tinkering and trial and error, but it helps if in addition to trying to build an airplane that flies you at the same time build a theory of flight control, as the Wright Brothers did (Bereiter, 2009). Similarly, it helps if in addition to experimenting with ways of conserving energy you have a theory that enables you to compute the total energy cost of, say, manufacturing a paper bag versus a plastic one. Theory building comes most clearly into its own, however, in solving problems of understanding. This is the kind of theory building that bears most directly on the main objectives of formal education. The children's theorizing about rainbows exemplifies building knowledge to solve a problem of understanding.

School students can build conceptual artifacts that they like to call theories and that can qualify as at least quasi-theories (Scardamalia et al., 2010). Typically their creations fall short of yielding testable predictions, but good student-generated theories are vulnerable to evidence, improvable, and discussable in terms of what they explain and fail to explain. They can meet standards of explanatory coherence (Thagard, 2000), which include internal coherence or logical consistency, coherence with accepted facts, and coherence with other theories. Theory building is not limited to science but can also play a part in history, social studies, and literature (Bereiter \& Scardamalia, in press). Explanations of historical or current events and interpretations of literary works are theories of particular cases rather than general theories, and they include human motives as explanatory elements, but they are subject to the same criteria of explanatory coherence as general theories. 
Theory building, we may say, is the primary way of living an intellectual life within the academic disciplines. It is what separates the historian from the antiquarian, the literary critic from the recreational reader, the ornithologist from the bird watcher. Not that there is anything wrong with antiquarianism, recreational reading, and bird watching. But we do not build educational institutions to teach them. We do build institutions to teach history, literature, and biology. And for students to acquire productive knowledge in these fields, there is no substitute for engaging them in actual productive uses of such disciplinary knowledge. There are many ways to do this, including teacher-assigned problems, practical projects such as toy and software construction, art work, dramatizations, and debates. But theory development has a special role in that it provides a direct path to further knowledge creation.

\section{Knowledge Building Discourse Compared to Wikipedia}

Outside the education world it is fairly easy to distinguish knowledge creation from learning. People generally do not get paid to learn. (When they do, it is because they have been temporarily relieved of regular work in order to enter an educational or training program.) They get paid for productive work, one variety of which is knowledge creation. All this gets seriously complicated when we consider knowledge creation by students, because the student's job (if you call it that) is learning. Knowledge Building is close to and comes to be confused with that broad category of educational approaches referred to in more than a million Web documents as "active learning" - approaches in which the learners take a cognitively and sometimes physically proactive as opposed to a mainly receptive role in their own learning (Bonwell \& Eison, 1991).

Wikis are a technology still relatively new in schools, but catching on fast. They provide an easy way for students to collaborate in producing a document and they also provide a discourse layer for the students to discuss issues arising from their joint enterprise. They have been heralded by some as an ideal technology for knowledge building (e.g., Cress \& Kimmerle, 2008). Because innovative uses of wikis are still appearing, we will not comment on this claim. But the most popular classroom use of wikis seems to be for producing documents similar to those that appear in Wikipedia, and so a comparison of this activity to Knowledge Building is appropriate and turns out to be informative.

Wikipedia is more than the compendium of encyclopedia-type entries that appear in it. It is a whole social organization out of which those entries are produced. Fundamentally, the sociocognitive process it represents is the antithesis of knowledge creation. This is not to fault it. Rather, it is to indicate why a comparison between Knowledge Building and the Wikipedia process should help clarify what is distinctive about Knowledge Building.

The Wikipedia organization has well-articulated content norms that essentially exclude knowledge creation (see http://en.wikipedia.org/wiki/Wikipedia:About\#Wikipedia_content_criteria). Would-be contributors are warned against reporting original research or presenting their own ideas. 
Controversies in a field are to be reported impartially. The goal is to represent the state of knowledge in an area, not to advance it. It is still possible, however, that some genuine knowledge creation could take place in developing a Wikipedia entry. This could occur if a difficult or counter-intuitive concept is presented in a way that makes it accessible to a wider audience than specialists in the field. It might center on a novel and enlightening analogy or it might consist of an explanation that links the difficult concept to familiar knowledge in a way that is faithful to the main idea. These are pedagogical inventions. They are the kinds of things that masterful lecturers are known to do.

Much of what is most striking in students' Knowledge Building amounts to pedagogical invention. It makes difficult ideas in a discipline more accessible to students and more applicable to questions the students actually wonder about. Here is an example: In one Grade $5 / 6$ class, students divided into small groups to investigate different forces. Two students undertook to study the strong nuclear force. They produced a two-paragraph note entered into a database accessible to others in the class. The first paragraph read as if copied from an encyclopedia article defining the strong nuclear force. The second paragraph described particle accelerators, said to be used to study the strong nuclear force. Their teacher entered a brief comment saying he did not get how the particle accelerator tells you about the strong nuclear force. The students went back to work and eventually produced a note explaining the connection. It ended with the memorable statement that when there is an explosion everything blows apart-except the atoms. This shows the strength of the strong nuclear force.

It is easy to criticize the students' concluding statement: Molecules generally do not blow apart in an explosion either; the strong nuclear force holds the nucleus of an atom together but not its electrons; furthermore, the concept itself has been superceded in modern physics. Nevertheless, the statement provides an insight that can have a powerful impact on how one thinks about matter. Students may already know that solid matter consists of atoms but they may not ever actually think of matter that way. Doing so-seeing the solids in the world around them as decomposable down to but not below the level of atoms-provides a perspective from which chemistry and atomic science and ultimately modern particle physics begin to come within their conceptual reach. What were marginally understood concepts start to become productive knowledge. While such understanding does not advance the frontiers of the discipline, it is a creative contribution to the local community, in form accessible to all members. And as knowledge networks become more prevalent local inventions will spread. In the current case the student-generated conception of strong nuclear force, which dates from pre-WWW times, could today reach a much larger population through a suitable social website. The new levels of "openness" currently being promoted in education have potential not only for wider dissemination of knowledge advances but also for feedback systems that can result in further improvement of the knowledge.

At one time we were drawn to the idea of having students, after they had completed a Knowledge Building unit, prepare their Knowledge Forum database to be passed on for the next year's students to build upon. We had hoped that, by documenting their knowledge advances 
as well as their difficulties, strategies, and problems yet to be solved, students would help the next year's class advance still farther, thus producing a cumulative effect similar to that in progressive disciplines. What we found, however, was that the students-evidently fearful of passing on naïve or wrong information or looking bad in the eyes of their successors - filtered out all their more novel and interesting insights and produced-what? Something that read like it was copied out of an encyclopedia. This happened in the days before Wikipedia, but we do not imagine that a wiki would have made the result any less disappointing. It was what the students left out that mattered, rather than what they put in. What they left out was their own ideas, their own efforts at knowledge creation. Our current efforts in development of Knowledge Forum technology have turned to engaging students in greater understanding of the "promisingness" of ideas and ways to enable them to rise within local knowledge networks and spread beyond.

Even though they have much in common, knowledge sharing (which Wikipedia excels at) is very different from knowledge creation. This is true even when both processes draw on the same information and produce outcomes that look similar. It is one thing to rack your brain to produce a coherent explanation of some phenomenon, using whatever information seems relevant. (That is theory building.) It is something else to rack your brain to produce an intelligible description of a theory you have learned about. It is one thing to work at improving your theory and another thing to work at improving your description of an extant theory (while endeavoring to leave the theory unchanged). If wikis are to be a tool for Knowledge Building (as opposed to being only a useful adjunct) they will need to be regulated by a radically different set of socio-cognitive norms from those of wikipedia.org. Those norms are intended to optimize knowledge sharing and to maximize the quality of shared knowledge. But optimizing knowledge creation calls for norms that encourage creative problem solving and treating all knowledge as potentially improvable.

\section{Related Approaches}

A number of modern educational approaches are close enough in spirit to Knowledge Building that they can be used as part of it. They do not, however, go the whole way toward engagement of students in theory building, in the production and improvement of community knowledge, and in the use of media and means to participate in distributed networks that characterize productive work in modern knowledge creating organizations. They do share with Knowledge Building a commitment to turning higher levels of agency over to students-giving students responsibility not only for the conduct of activities but also for their cognitive essences. The closest in spirit is constructionism, conceived along Piagetian lines by Papert (1991), implemented in Logo, and carried forward by former students including diSessa (2000), Resnick (1994), and Kafai (2006). As the name "constructionism" implies, the key idea is that students should be builders rather than only users of artifacts. Papert included theories among the kinds of "public entities" students might build, and this would make constructionism, from a theoretical perspective, compatible with Knowledge Building. 
The closest to theory building has been computer-based modeling of quantitative relations (diSessa, 2000; Wilensky \& Reisman, 2006). This is an important part of creative scientific work. However, in educational practice the problems are usually ones posed by the teacher and they are not part of young people's normal efforts to make sense of the world. The problems of explanation that drive student theorizing are ones that call for qualitative theories (dekleer \& Brown, 1985) - causal theories often in a narrative form: "The steam comes in here and pushes on the piston, which turns the wheel and opens the return valve..." and so on.

"Learning Science by Design" (Kolodner, 2006) is another neighbour of Knowledge Building. As with constructionism, its focus is building things that work, but the construction tasks represent problems to be solved: for instance, building a toy car that not only travels but is able to negotiate a rocky terrain. Learning Science by Design could be characterized as elementary knowledge building for engineering. It could also be called knowledge building for invention, except that for practical reasons all of these hands-on constructionist activities require so much pre-structuring of tools, materials, and problems, that scope for invention and students taking charge at the highest levels is limited, as is the possibility that such work will become the mainstay of school life.

"Philosophy for Children," as developed over the years by Lipman (1988), aims at turning the classroom into a community of inquiry, with reflective thought as the guiding principle. A Knowledge Building classroom should have this character, and Lipman's tested methods for making epistemological concepts accessible to young learners can be valuable in achieving this objective. Philosophy for Children differs from Knowledge Building in that its focus is the traditional philosophical focus on beliefs rather than a focus on design and production of new knowledge. Design, however, is an idea that runs through all the varied work of Perkins (1981, 1986, 1998), providing an important conceptual substrate for Knowledge Building. Similarly, the Galileo Educational Network (http://www.galileo.org/) aims for teaching for deep understanding through inquiry-based projects with a strong design component. Finally, "Communities of Learners" (Brown \& Campione, 1994) and Knowledge Building aspire to similar educational outcomes. "Community of Learners" pursues them through the route of learners as teachers rather than participants in a community of inventors or theory builders. It therefore provides a comparison approach that can help in understanding both the relation between Knowledge Building and learning and their underlying differences (Scardamalia \& Bereiter, 2007). The differences are manifested in the fact that in Communities of Learners students collaborate to produce textbooks to teach other students, whereas in Knowledge Building students collaborate to solve knowledge problems, using media to situate ideas in distributed knowledge networks.

While Knowledge Building has kinship with only a limited number of other approaches, it is at least compatible with others. For instance, lectures, demonstrations, and assigned readings can have a place within a Knowledge Building framework, albeit as adjuncts rather than the main fare. The same goes for assigned problems. There are illuminating and thought-provoking problems students are unlikely to think of by themselves but that engender productive 
knowledge. (Mathematicians distinguish puzzles from problems. With puzzles the solutions are of no consequence and so only the process matters, whereas with genuine problems the solutions are of value in developing understanding.) In an effort to bring the worlds of powerful knowledge resources into greater alignment with students' powerful ideas, we are working with teams building open learning environments, so as to make any web object an object of Knowledge Building discourse and, in turn, create sophisticated models for constructive use of authoritative sources (constructive use of these resources is a Knowledge Building principlesee "A Brief History of Knowledge Building," present issue).

Work on learning and thinking skills may have a place in Knowledge Building, as well, although if allowed to become the tail that wags the dog it can seriously divert energy from more substantial work. If students are engaged in sufficiently varied Knowledge Building, which includes theory building along with designing, inventing, programming, and planning, and if in the process they are doing plenty of communicating, educators need to ask what is being left out that could call for special attention to thinking skills. As several articles in this special issue demonstrate, a broad array of $21^{\text {st }}$ century skills are by-products of Knowledge Building (see, for example, Gan, Scardamalia, Hong, \& Zhang; present issue; McAuley, 2009; Moss \& Beatty, present issue; Sun, Zhang, \& Scardamalia, present issue). Knowledge Building is incompatible with the mile-wide, inch-deep curriculum, with its demands for rapid coverage of a multitude of topics - but then, isn't everybody against this? Knowledge Building can absorb a number of other approaches by harnessing them to the central goal of advancing the creation of community knowledge. It is much less likely that other approaches can absorb Knowledge Building, for that would involve a fundamental restructuring of the other approach so as to make idea generation and idea improvement rather than activities and procedures the center of classroom life.

In this article we have tried to elaborate the concept of knowledge creation in a way that makes it plausible that naïve learners can create knowledge to aid in their creation of further knowledge, and that classrooms can become knowledge creating organizations in their own right. Knowledge creation feeding knowledge creation is the dynamic on which societies of the $21^{\text {st }}$ century increasingly depend to deal with their mounting problems (Homer-Dixon, 2006). As an educational approach, Knowledge Building gives students the chance to be part of this dynamic, living the life of a knowledge society rather than only preparing to live it.

\section{References}

Bereiter, C. (2009). Innovation in the absence of principled knowledge: The case of the Wright Brothers. Creativity and Innovation Management, 18(3), 234-241.

Bereiter, C., \& Scardamalia, M. (in press). Theory building and the pursuit of understanding in history, social studies, and literature. In M. J. Lawson \& J. R. Kirby (Eds.), The quality of learning. New York: Cambridge University Press.

Bonwell, C., \& Eison, J. (1991). Active learning: Creating excitement in the classroom. AEHE-ERIC 
Higher Education Report No.1. Washington, D.C.: Jossey-Bass.

Brown, A. L., \& Campione, J. C. (1994). Guided discovery in a community of learners. In K. McGilley (Ed.), Classroom lessons: Integrating cognitive theory and classroom practice (pp. 229-270). Cambridge, MA: MIT Press.

Case, R. (Ed.). (1992). The mind's staircase: Stages in the development of human intelligence. Hillsdale, NJ: Lawrence Erlbaum Associates.

Case, R., \& Okamoto, Y. (1996). The role of central conceptual structures in the development of children's thought. Monographs of the Society for Research in Child Development, 61(1-2).

Collins, A., \& Ferguson, W. (1993). Epistemic forms and epistemic games: Structures and strategies for guiding inquiry. Educational Psychologist, 28(1), 25-42.

Cress, U., \& Kimmerle, J. (2008). A systemic and cognitive view on collaborative Knowledge Building with wikis. International Journal of Computer-Supported Collaborative Learning, 3, 105-122.

deKleer, J., \& Brown, J. S. (1985). A qualitative physics based on confluences. In D. G. Bobrow (Ed.), Qualitative reasoning about physical systems (pp. 7-84). Cambridge, MA: MIT Press.

Dennett, D. C. (1995). Darwin's dangerous idea: Evolution and the meanings of life. New York: Simon \& Schuster.

diSessa, A. A. (2000). Changing mind: Computers, learning, and literacy. Cambridge, MA: MIT Press.

Gan, Y. C., Scardamalia, M., Hong, H. Y., \& Zhang, J. (2010). Making thinking visible: Growth in graphical literacy, Grades 3 to 4. Canadian Journal of Learning and Technology, 36(1).

Homer-Dixon, T. (2006). The upside of down: Catastrophe, creativity, and the renewal of civilization. Washington, DC: Island Press.

Kafai, Y. B. (2006). Constructionism. In K. Sawyer (Ed.), Cambridge Handbook of the Learning Sciences (pp. 35-60). New York: Cambridge University Press.

Kolodner, J. L. (2006). Case-based reasoning. In K. Sawyer (Ed.), Cambridge Handbook of the Learning Sciences (pp. 225-242). New York: Cambridge University Press.

Lipman, M. (1988). Philosophy goes to school. Philadelphia: Temple University Press.

McAuley, A. (2009). Knowledge Building in an aboriginal context. Canadian Journal of Learning and Technology, 35(1). Retrieved from http://www.cjlt.ca/index.php/cjlt/article/view/514

Moss, J., \& Beatty, R. (2010). Knowledge Building and mathematics: Shifting the responsibility for knowledge advancement and engagement. Canadian Journal of Learning and Technology, 36(1). 
Ohlsson, S. (1993). Abstract schemas. Educational Psychologist, 28(1), 51-61.

Papert, S. (1991). Situating constructionism. In I. Harel \& S. Papert (Eds.), Constructionism (pp. 1-14). Hillsdale, NJ: Lawrence Erlbaum Associates.

Perkins, D.N. (1981). The mind's best work. Cambridge, MA: Harvard University Press.

Perkins, D.N. (1986). Knowledge as design. Mahwah, NJ: Lawrence Erlbaum Associates, Inc.

Perkins, D.N. (1998). What is understanding? In Wiske, M.S. (Ed.), Teaching for understanding: Linking research with practice (pp. 39-57). San Francisco, CA: Jossey-Bass.

Resnick, M. (1994). Turtles, termites, and traffic jams: Explorations in massively parallel microworlds. Cambridge, MA: MIT Press.

Scardamalia, M., Bereiter, C., Chuy, M., Prinsen, F., Resendes, M., \& Teplovs, C. (2010). Understanding the nature of science and scientific progress: A theory-building approach. Canadian Council on Learning (CCL) website. Web document, retrieved 30 August, 2010, from http://www.cclcca.ca/CCL/Research/FundedResearch/201008ScardamaliaScience.html

Scardamalia, M., \& Bereiter, C. (2007). Fostering communities of learners and Knowledge Building: An interrupted dialogue. In J. C. Campione, K. E. Metz, \& A. S. Palincsar (Eds.), Children's learning in the laboratory and in the classroom: Essays in honor of Ann Brown (pp. 197-212). Mahwah, NJ: Erlbaum.

Scardamalia, M., \& Bereiter, C. (2010). A brief history of Knowledge Building. Canadian Journal of Learning and Technology, 36(1).

Simonton, D. K. (1999). Origins of genius: Darwinian perspectives on creativity. New York: Oxford University Press.

Snow, C. P. (1959). The two cultures and the scientific revolution. New York: Cambridge University Press.

Sun, Y., Zhang, J., \& Scardamalia, M. (2010). Developing deep understanding and literacy while addressing a gender-based literacy gap. Canadian Journal of Learning and Technology, 36(1).

Thagard, P. (2000). Coherence in thought and action. Cambridge, MA: MIT Press.

Wandersee, J., Mintzes, J., \& Novak, J. (1994). Research on alternative conceptions in science. In D. Gabel (Ed.), Handbook of research on science teaching and learning (pp. 177-210). New York: Macmillan.

Wikipedia Content Criteria. (n.d.). In Wikipedia. Retrieved August 31, 2010, from http://en.wikipedia.org/wiki/Wikipedia:About\#Wikipedia_content_criteria 
Wilensky, U., \& Reisman, K. (2006). Thinking like a wolf, a sheep, or a firefly: Learning biology through constructing and testing computational theories-an embodied modeling approach. Cognition and Instruction, 24(2), 171-209.

Zhang, J., Scardamalia, M., Reeve, R., \& Messina, R. (2009). Designs for collective cognitive responsibility in Knowledge Building communities. Journal of the Learning Sciences, 18(1), 7-44.

\footnotetext{
${ }^{i}$ As an informal test of productive knowledge of rational numbers, we have from time to time over the years posed to educated adults the problem of how to measure 1/7 of a foot, using an ordinary foot ruler marked in sixteenths of an inch. Responses have ranged from utter cluelessness to being able to calculate a decimal fraction, e.g., 1.714, but then being unable to find that point on a ruler-and often failing to understand why 1.714 is not an adequate solution to the problem. A few grasp that the problem is converting sevenths to sixteenths, but they find themselves unable to do it.

ii There is illusory productivity in that Algebra I is essential for success in Algebra II, which in turn may be essential for survival in Calculus I. But except for the few students who manage to work out for themselves what it all means, this is a road to nowhere, a fact that becomes apparent if the students venture into an advanced mathematics course where understanding is required.
} 